Revue d'histoire de l'Amérique française

DEYUE D.HISTOIRE DE L'AMÉRIQUE FRANÇAISE

\title{
CHARLAND, Jean-Pierre et Nicole THIVIERGE, Bibliographie de l'enseignement professionnel 1850-1980. Québec, Institut québécois de recherche sur la culture, 1982. 282 p. Coll. "Instruments de travail ", no 3. \$14.00.
}

\section{Marcel Leduc}

Volume 36, numéro 3, décembre 1982

URI : https://id.erudit.org/iderudit/304083ar

DOI : https://doi.org/10.7202/304083ar

Aller au sommaire du numéro

Éditeur(s)

Institut d'histoire de l'Amérique française

ISSN

0035-2357 (imprimé)

1492-1383 (numérique)

Découvrir la revue

Citer ce compte rendu

Leduc, M. (1982). Compte rendu de [CHARLAND, Jean-Pierre et Nicole THIVIERGE, Bibliographie de l'enseignement professionnel 1850-1980. Québec, Institut québécois de recherche sur la culture, 1982. 282 p. Coll. « Instruments de travail ", no 3. \$14.00.] Revue d'histoire de l'Amérique française, 36(3),

447-447. https://doi.org/10.7202/304083ar d'utilisation que vous pouvez consulter en ligne. 
CHARLAND, Jean-Pierre et Nicole THIVIERGE. Bibliographie de l'enseignement professionnel 1850-1980. Québec, Institut québécois de recherche sur la culture, 1982. 282 p. Coll. "Instruments de travail», no 3. $\$ 14.00$

Ces dernières années plusieurs universitaires ont consacré des études à différents aspects de l'évolution du système d'éducation québécois. Deux d'entre eux, Jean-Pierre Charland et Nicole Thivierge, nous ont récemment présenté un ouvrage de référence sur l'enseignement professionnel. Les auteurs, avec la collaboration de Claire Côté et Jacques Saint-Pierre - ce dernier faisait partie de l'équipe de l'«Annexe historique» à la Commission Jean - mettent à notre disposition quelque trois mille références. Voilà une bibliographie qui, à première vue, nous semble exhaustive. Pourtant quelques lacunes apparaissent. Entre autres les études concernant le milieu syndical font défaut de même que celles sur la formation en entreprises. D'aucuns diront que nous débordons probablement du cadre de recherche des auteurs. Il n'en est rien puisque certains titres présentés le sont sans raison apparente. De plus, la recherche universitaire, thèses de maîtrise ou de doctorat, semble, selon ce répertoire, concentrée à l'Université Laval. Les thèses identifiées nous le laissent malheureusement croire. Les autres centres universitaires québécois sont à toute fin pratique délaissés, ce qu'on s'explique difficilement. Il aurait été souhaitable que les auteurs mettent à profit entre autres les recherches bibliographiques entreprises dans le cadre de la Commission d'étude sur la formation des adultes (Commission Jean). Dans son ensemble, la compilation de Charland et Thivierge sera d'un apport certain pour toutes les personnes intéressées par le sujet. Cet outil de référence, le premier dans ce champ d'étude de l'enseignement, démontre la diversité de la recherche et s'avère essentiel aux chercheurs. 